\title{
SyNTACTIC PATTERNS IN WELSH AND ENGLISH NiCKNAMES - A COMPARISON
}

\author{
KATARZYNA JĘDRZEJEWSKA-PYSZCZAK
}

\section{Introduction}

As my paper deals with syntactic patterns of Welsh and English nicknames I would like to start with an introductory note on what constitutes the notion of nickname (llysenw in Welsh). In short, nicknames are linguistic expressions that enable identification in cases of unclear reference by means of singling out. As semantically motivated, they are bestowed upon individuals by other members of the community with a view to highlighting prominent and unique features of their bearers. The inspiration for nicknames comes from a number of sources. They predominantly refer to appearance, physical and mental attributes, traits of character and habits, not to mention whereabouts, place of birth, characteristic forms of linguistic expression or the nature of occupation. Any single event or peculiar situation that caught the imagination of people is likely to be expressed by means of a telling nickname. Consequently, nicknames commonly carry considerable emotional load, be it positive or negative. The current study employs the term nickname in its primary sense, i.e. such of an identification tool, with any additional meaning of the term treated as irrelevant.

Two aspects of the linguistic make-up of Welsh and English nicknames are dealt with in the paper, namely the underlying word classes and word order patterns. With respect to the analysed Welsh corpora, it needs to be noted that both English-based Welsh nicknames as well as those Welsh only are subject to scrutiny. The Welsh language data is taken from Myrddin ap Dafydd's (1997) Llysenwau. Casgliad o lysenwau Cymraeg a gofnodwyd yn y cylchgrawn Llafar Gwlad [Nicknames. Collection of Welsh nicknames which were recorded in the journal Llafar Gwlad] for Middle Welsh and Modern Welsh nicknames as well as Roy Noble's (1997) Roy Noble's Welsh Nicknames for contemporary nicknames only. Four major dictionaries from which English nicknames for the present investigation were excerpted are those of Julian Franklyn (1962), L. G. Pine (1984), Nigel Rees and Vernon Noble (1985) as well as Andrew Delahunty (2006). 


\section{Welsh nicknames}

With respect to Welsh nicknames formed through the medium of Welsh, the most prevailing pattern is that of (I) proper noun postmodification where the original designation is followed by semantic specification. Frequent realisations of this type include several distinct patterns which I illustrate in the following way:

a) proper noun (first name) + proper noun (first name), e.g.

Ted Betsi "Ted of Betsi", Shoni Gladys "Shoni of Gladys", George Peggy "George of Peggy"

b) proper noun (first name) + proper noun (first name) + proper noun (first name), e.g.

Lisi Ann Jane "Lisi (the daughter) of Ann (the daughter) of Jane", Twm Siôn Cati "Twm (the son) of Siôn (the son of) Cati"

It is interesting to observe that the Welsh tend to refer to women ancestors in the identification of individuals. Similarly, it is more common for men to be defined with respect to their wives than the other way round. Such method could be implemented to counterbalance the predominance of the form $a b / a p+$ male ancestor (i.e. "the son of") both in the official registers (as surnames) and in bardic names.

c) proper noun (first name) + proper noun (place name), e.g.

Siôn Ewrop "Siôn of Europe", Wil Almwch "Wil of Almwch", Tomi Harlech "Tomi of Harlech", Jac Pen Bont "Jac of Pen Bont”, Ieuan Bryn Hafod "Ieuan of Bryn Hafod"

d) proper noun (first name) + common noun in the singular, e.g. Dafydd Menyn "Dafydd Butter”, Margiad Pwyth "Margiad Stitch”, Idwal Leitning "Idwal Lightning", Jack Sebon "Jack Soap", Joe Wisgi "Joe Whisky", Dei Dîr "Dei Water", Gari Wordob "Gari Wardrobe", Howard Beic "Howard Bike", Guto Pryder "Guto Worry", Jac Corff "Jac Corpse”, Robin Soldiwr "Robin Soldier”, Ifan Brenin "Ifan King”

e) proper noun (first name) + common noun in the plural, e.g. John Blodau "John Flowers", Bethan Jygs "Bethan Jugs", Bethan Cyrls "Bethan Curls"

f) proper noun (first name) + common noun + adjective, e.g. Ned Stori Gron "Ned Shaggy Dog Story”, Aled Pen Fflat "Aled Flat Head", Glyn Cadach Gwyn "Glyn White Handkerchief", John Pry Gwyllt "John Wild Worm", Margiad Calon Fawr "Margiad Big Heart”, George Papur 
Newydd "George New Newspaper", Wil Pen Cam "Wil Head Crooked to One Side”, Tomi Crys Glan “Tommi Clean Shirt”

The above formations all represent proper genitival constructions in Welsh where the lenition is missing in the second element. Lenition in the case of genitive is a productive pattern to be observed, however, in Middle Welsh.

g) proper noun (first name) + adjective, e.g.

Hefin Hapus "Hefin the Happy", Dafyd Dwp "Dafydd the Silly", Iorwerth Hagr "Iorwerth the Ugly", Madog Frych "Madog the Spotted", Eirys Beriglys "Eirys the Dangerous", Hywel Fain "Hywel the Thin", Meri Slei "Meri the Sly", Jane Wirion "Jane the Innocent/Foolish"

h) proper noun (first name/surname) + definite article $y / y r+$ common noun, e.g.

Robert yr Oen "(The) Robert the Lamb”, Hefin yr Afanc "(The) Hefin the Beaver", Chris Y Brenin "(The) Chris the King”, Dic Yr Hafod "(The) Dic the Summer Pasture", Harold y Wats "(The) Harold the Watch", Ifan $y$ Torrwr "(The) Ifan the Cutter", Jones y Bara "Jones the Bread", Mari’r Gath "Mari the Cat", Jones y Siop "Jones the Shop"

i) proper noun (first name) + cardinal + common noun, e.g.

Bob Tri Chwarter "Bob Three Quarters", Dic Dau Dad "Dic Two Dads", Bob Un Glust "Bob One Ear”, Dic Dau Fol "Dic Two Bellies", Tomi Dau Funud "Tomi Two Minutes"

j) proper noun (first name) + verb, e.g.

Wil Sgrech from sgrech "to scratch", Twm Cloi from cloi "to close"

k) proper noun (first name) + proper noun (surname) + verb, e.g. Margiad Williams Golchi from golchi "to wash"

l) proper noun (first name) + verb + common noun, e.g.

Kitty Codi Sbîd "Kitty who accelerates", Sam Boddi Cathod "Sam who drowns cats", Guto Gyrru Mellt "Guto who drives (as quick) as a lighting", Irene Cachu Matshus "Irene who defecates matches"

m) proper noun (first name) + verb + adverb, e.g.

Meri Piso'n Bell "Mary who urinates far"

(II) There are a few pre-modified proper nouns as in: common noun + proper noun (first) name, e.g.

Tyddyn Llywelyn “Llywelyn’s Small Farm”, Bwthyn Betsi “Betsi’s Small Cottage”. 
(III) The postmodification of common nouns is less productive than in the case of proper nouns, and, yet, it occurs, as in:

a) common noun + adjective, e.g.

Llyfant Melyn "Yellow Toad", Traed Mawr "Big Feet", Llygoden Fawr "Big Mouse" (Rat)

b) common noun + common noun, e.g.

Mab Rhywun "Son of Somebody", Pen March "Head of a Horse", Coesau Bwrdd "Legs of Table".

(IV) Similarly rare are Welsh nicknames which involve only common nouns in the singular, e.g.

Tecell "Kettle”, Ŝ̂n "Noise”, Parot "Parrot”.

It should be noted here that the examples of III and IV additionally display the lack of the personal name in the applied secondary designation.

The scarcity of common noun-based nicknames in Welsh does not seem too surprising, however, when bearing in mind that the identifying potential of such referring expressions is greatly diminished.

Apart from their mother tongue, the Welsh employ the English language in order to arrive at alternative designations of people. The contribution of English is substantial, yet it does not overshadow the great bulk of nicknames formed through the use of the Welsh language.

Patterns comprising English lexicon are as follows:

(I) Post-modified proper noun:

a) proper noun (first name) + common noun in the singular, e.g. Iwan Ring, Dai Egg, Dai Cube, Mary Peninsula, Dai Sky, Tommy Bandit, Dai Echo, George Blood, Huw Champion, John Boxer, Meri Snob, Hughes Trash, Morris Yankee, Kenny Custard, Wil Fish

b) proper noun (first name) + common noun in the plural, e.g. Johnny Minutes, Tom Cockles, Jack Flags, Sami Sticks, Helen Melons, Johnny Skins, Dic Points, Bryn Chops

c) proper noun (first name/surname) + definite article the + common noun, e.g.

John the Box, Morgan the Lawyer, Stan the Can, Ivor the Jiver 
d) proper noun (first name) + common noun in the singular/plural + conjunction and + common noun in the singular/plural, e.g.

Bil Cock and Hen, Arwel Butter and Eggs, Ivor Apples and Pears, Dai Book and Pencil

e) proper noun (first name) + cardinal + common noun in the singular/plural, e.g.

John Ten Coats, Willie Three Piece, Will Eighteen Months, Dai One Eye

f) proper noun (first name/surname) + adjective + common noun, e.g. Herbie Good Boy, Dai Pretty Trousers, Dai Full Pelt, Ann Bloody Liar, Jones Busy Day, Lizzie Ann Old Face, Jane Cold Rols, Dai White Hunter, Dai Electric Hare, Johnny Odd Stocking, Fanny Spare Parts, Dai Quiet Wedding, John Bad English

g) proper noun (first name/surname) + adjective, e.g.

Mark Mature, Tom Evans Hard, Dai North, Maggie Elastic, Jack Divine, Dai Damp

h) proper noun (first name) + adjective + conjunction and + adjective, e.g.

Ernie Black and White

i) proper noun (first name) + verb + adverb, e.g. Ann Walk Nicely

(II) Pre-modified proper noun:

a) adjective + proper noun (first name/surname), e.g.

Clever Evans, Sharky Davies, Sweaty Betty, Dirty Dic, Greasy Annie, Handsome Harry, Trendi Wendy, Sweet Wiliam

b) verb + pronoun + proper noun - first name, e.g. Sack-em Jack

\section{English nicknames}

English nicknames are markedly different from their Welsh counterparts with respect to over-reliance on common nouns and a subsequent underrepresentation of proper nouns as revealed by the corpora studied here.

Contrary to Welsh nicknames, English personal designations in the majority incorporate common nouns, either unaccompanied or subject to premodification. Hence, the following categorization emerges: 
(I) Common noun in the singular, e.g. Shrimp, Balloon, Tank, Sausage, Fury, Ginger, Dazzler, Giraffe, Chin, Bee, Thumper, Flame, Cane, Barrel, Pincher

(II) Common noun in the plural, e.g.

Bumps, Dickles, Freckles, Carrots, Needles, Guts

(III) Pre-modified common noun:

a) definite article the + common noun in the singular, e.g.

The Boar, The Master, The Professor, The Choirboy, The Gnome, The Maiden, The Crab, The Goat

b) common noun + common noun, e.g.

Plum Pudding, Drain Pipe, Razor Blade, Eye Balls, Fire Bucket, Fire Head, Jelly Belly, Pudding Pie, Steam Roller, Fuse Wire, Human Tank, Copper Crust, Glass Eyes, Action Man

c) adjective + common noun in the singular/plural, e.g.

Mad Head, Greedy Pig, Old Bags, Ruby Nose, Black Ditch, Hollow Legs, Crazy Horse, Admirable Doctor, Chubby Cheeks

d) definite article the + adjective + common noun in the singular, e.g. The Long Fellow, The Merciless Doctor, The Black Panther, The Black Diamond, The Gloomy Dean, The Bloody Butcher, The Bald Eagle

e) cardinal + common noun in the plural , e.g. Four Eyes, Two Brains

f) proper noun (place name) + common noun in the singular, e.g. Birmingham Poet, Bristol Boy, Bideford Postman

g) definite article the + proper noun (place name) + common noun in the singular, e.g.

The Preston Plumber, The Jersey Lily

Proper nouns make a rare appearance in English nicknaming patterns. The available instances yet again point to the prevalence of premodified proprial expressions at the expense of postmodified structures:

a) common noun + proper noun (first name/ surname), e.g.

Baby Charles, Farmer George, Finality John, Flash Harry, Prosperity Robinson, Dictionary Johnson 
b) adjective + proper noun (first name), e.g.

Silly Billy, Tiny Tom, Hungry Horace, Black Tom, Radical Jack, Red Elen, English Solomon, British Cicero, English Achilles

Rare cases of a qualifier which follows the proper noun include:

a) proper noun (first name) + definite article the + common noun, e.g. Guy the Gorilla, Dennis the Menace, Eddie the Eagle

b) proper noun (first name) + common noun, e.g. John Bull

Genitival constructions among English nicknames seem to be restricted to of-phrases denoting the semantic dimensions of origin, possession and quality as in:

a) common noun + preposition of + proper noun (place name), e.g. Beauty of Buttermere, Apostle of England, Bard of Avon, Man of Ross, Novelist of Wessex

b) common noun + preposition of + common noun, e.g. Bard of Memory, Queen of Hearts

c) (definite article the) + common noun + preposition of + common noun, e.g.

The Lion of Justice, The Prince of Darkness, Bard of Hope

\section{Conclusion}

The analysis of Welsh and English nicknames with reference to word classes that underlie these linguistic constructions gives important clues as to the function of nicknaming in both languages. Firstly, it becomes evident that Welsh llysenwau retain their identificatory function and come into being with a primary view of enabling unambiguous nomination of individual community members given the observation that the proper noun is the indispensible element in the structure of a Welsh nickname. This is harmed in a handful of examples only. In contrast, English denominations display a reverse trend, namely instead of the proper noun it is mostly the common noun that constitutes the core of the formation.

Secondly, what follows is that the linguistic reality of nicknaming patterns might be considered as more context-sensitive in the English language, while the inherent presence of official designations, i.e. the first/second name or the surname, in Welsh designations increases the autonomy of reference. It could be anticipated then that English nicknames would outweigh their Welsh counterparts with regard to descriptive content 
employed to compensate for the weakening of direct reference as otherwise guaranteed by the inclusion of the name proper. Quite to the contrary, Welsh llysenwau resort to more flowery language, thus manifesting greater elaboration of form. English coinages represent a focus on succinctness and matter-of-factness which often creates the impression of a less or more official title.

Thirdly, in connection with the criterion of word order, it can be stated that the two systems typical of Welsh and English, namely VSO and SVO, remain by and large intact in more complex nickname formations. This observation is all the more valid given the linguistic landscape of the British Isles with the English language functioning as the dominating and Welsh as the dominated language. The native tongue of Welshmen retains the internal structure of Welsh noun phrases in coined nicknames. What prevails, therefore, is the postmodification of proper nouns by means of common nouns, adjectives as well as verb phrases. The instances or premodified proper nouns are restricted to genitive constructions, also Welsh specific. The influence of English upon Welsh is reflected in English-based llysenwau, yet its impact is not as profound as it might be expected from a dominating language. Despite the code switching the Welsh persist in including proper nouns in their description of individuals. Moreover, alongside cases of premodification which are of English provenance such as Sweaty Betty or Handsome Harry, the Welsh word order is often also imposed upon the English constituent parts as in John Evans Hard or Ernie Black and White.

Adam Mickiewicz University, Poznań, Poland 


\section{References}

Algeo, J., 1973, On Defining the Proper Name, Gainesville: University of Florida Press.

Allerton, D.J., 1987, 'The Linguistic and Sociolinguistic Status of Proper Names', Journal of Pragmatics 11, 61-92.

Ap Dafydd, M., 1995, 'Glasenwau ar hyd y Canrifoedd' [Nicknames through the Centuries], Llafar Gwlad 48, 16-17.

Ap Dafydd, M., 1997, Llysenwau. Casgliad o lysenwau Cymraeg a gofnodwyd yn y cylchgrawn "Llafar Gwlad", Llanrwst: Gwasg Carreg Gwalch.

Crystal, D., 1995, The Cambridge Encyclopaedia of the English Language, Cambridge: Cambridge University Press.

Crystal, D., 2003, A Dictionary of Linguistics and Phonetics, Oxford: Basil Blackwell.

Cuddon, J.A., 1998, A Dictionary of Literary Terms and Literary Theory, Oxford: Blackwell.

Delahunty, A., 2006, Oxford Dictionary of Nicknames, Oxford: Oxford University Press.

Eichler, E., Hilty G., Löffler H., Steger, H., \& Zgusta L., eds., 1996, Namenforschung. Ein internationationales Handbuch der Onomastik, Berlin: Walter de Gruyter.

Franklyn, J., 1962, A Dictionary of Nicknames, Worcester: The Trinity Press.

Noble, R., 1997, Roy Noble's Welsh Nicknames, Cardiff: Western Mail Books.

Pine, L.G., 1984, A Dictionary of Nicknames, London: Routledge \& Kegan Paul.

Reaney, P. H., 1997, A Dictionary of English Surnames, Oxford: Oxford University Press.

Rees, N. \& Noble, V., 1985, A Who's Who of Nicknames, London: George Allen \& Unwin.

Room, A., 1986, A Dictionary of True Etymologies, London: Routledge and Kegan Paul.

Skeat, W.W., 1963, An Etymological Dictionary of the English Language, Oxford: The Clarendon Press. 